\section{Commentary: Be Samwise}

\author{
Tomasz A. Timek, MD, PhD
}

Repair of degenerative mitral valve regurgitation offers durable and predictable patient outcomes and has become the gold standard of surgical therapy. ${ }^{1}$ As the surgical tool box for repairing the degenerative valve is extensive, ${ }^{2}$ the alterations in the 3 -dimensional relationships of valvular and subvalvular structures become more complex and less predictable. Systolic anterior motion (SAM) of the mitral valve has been described postrepair of degenerative valves and can lead to left ventricular outflow tract (LVOT) obstruction and mitral regurgitation (MR). ${ }^{3}$ In the current issue of the Journal, Ashikhmina and colleagues ${ }^{4}$ present a large series of 761 degenerative mitral valve repairs, with $98(13 \%)$ patients developing intraoperative SAM after weaning from cardiopulmonary bypass. Only 7 patients needed surgical correction of SAM, and with this predominantly conservative approach, the authors were able to achieve good mid-term outcomes in follow-up.

Conservative approach to treating SAM has been advocated by others. De Bonis and colleagues ${ }^{5}$ reported a need for second crossclamp in 22 of $2318(0.94 \%)$ degenerative repairs due to SAM, which is strikingly similar to the 7 of $761(0.92 \%)$ reported in the current study. El-Eshmawi and colleagues ${ }^{6}$ reported a lower rate of 5 of 1917 $(0.26 \%)$, but the inclusion for SAM reintervention was based on residual MR, not LVOT obstruction. Although the rate of SAM was quite high in the study of Ashikhmina and colleagues, at $13 \%$, this may be due to a too broad a definition that included any protrusion of the anterior mitral leaflet or chordal apparatus into the LVOT without necessarily causing concomitant obstruction. In a previous report from the Mayo clinic, ${ }^{7}$ the incidence of SAM was $11.1 \%$ in 1589 degenerative patients, but only 20 patients had

From the Division of Cardiothoracic Surgery, Spectrum Health, Michigan State University College of Human Medicine, Grand Rapids, Mich

Disclosures: Author has nothing to disclose with regard to commercial support.

Received for publication Jan 23, 2020; accepted for publication Jan 26, 2020; available ahead of print Feb 7, 2020.

Address for reprints: Tomasz A. Timek, MD, PhD, Division of Cardiothoracic Surgery, Spectrum Health, Michigan State University College of Human Medicine, 100 Michigan Ave NE, Grand Rapids, MI (E-mail: tomasz.timek@ spectrumhealth.org).

J Thorac Cardiovasc Surg 2021;162:582-3

$0022-5223 / \$ 36.00$

Copyright (c) 2020 by The American Association for Thoracic Surgery

https://doi.org/10.1016/j.jtcvs.2020.01.073

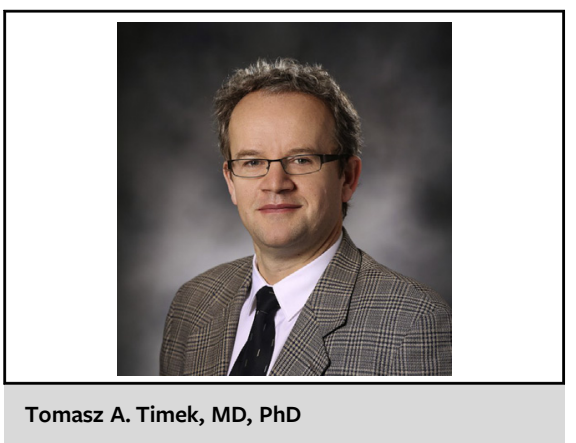

CENTRAL MESSAGE

Intraoperative systolic anterior motion of the mitral valve after degenerative repair is usually a benign phenomenon that rarely needs surgical correction.

concomitant LVOT obstruction. The current authors used a $63-\mathrm{mm}$ posterior band to reinforce the mitral repair, which corresponds to a $28-\mathrm{mm}$ size standard prosthesis, yet most large series of degenerative repairs report using more sizable devices. ${ }^{8}$ Using a smaller-sized annuloplasty may predispose the leaflet coaptation point being displaced anteriorly, although this risk may be lower with posterior bands. ${ }^{9}$ Perhaps most reassuring from the authors' data is the fate of the 28 patients who had persistent SAM on discharge echocardiography, as their rate of mitral reintervention was not different from patients who never developed SAM. However, these patients with persistent SAM had no significant LVOT obstruction, with a mean gradient of only $6.8 \mathrm{~mm} \mathrm{Hg}$, bringing into question the clinical significance of these echocardiographic findings. Small chamber size and reduced ratio of anterior to posterior leaflet height were identified by the authors as potential predictors of SAM but not specific to those patients who required surgical correction. As such, the authors did not recommend any prophylactic measures based on preoperative characteristics to avoid intraoperative SAM. Although surgical prophylaxis is wisely discouraged, anesthetic preventive management should be fostered, as judicious use of fluids, avoidance of inotropes, and chronotropic control in great majority of cases will abolish SAM before it arises.

The current study provides further evidence that intraoperative SAM after degenerative repair is usually a benign phenomenon that in majority of cases resolves with conservative measures. Rare surgical intervention may be needed, but restraint should otherwise be exercised, especially when 
neither LVOT obstruction nor significant MR are present. Stay cool, be wise.

\section{References}

1. Carpentier A. Cardiac valve surgery-the "French correction" J Thorac Cardiovasc Surg. 1983;86:323-37.

2. Schubert SA, Mehaffey JH, Charles EJ, Kron IL. Mitral valve repair: the French correction versus the American correction. Surg Clin North Am. 2017;97:867-88.

3. Lee KS, Stewart WJ, Lever HM, Underwood PL, Cosgrove DM. Mechanism of outflow tract obstruction causing failed mitral valve repair. Anterior displacement of leaflet coaptation. Circulation. 1993;88:II24-9.

4. Ashikhmina E, Schaff HV, Daly RC, Stulak JM, Greason KL, Michelena HI, et al. Risk factors and progression of systolic anterior motion after mitral valve repair. J Thorac Cardiovasc Surg. 2021;162:567-77.
5. De Bonis M, Lapenna E, Giambuzzi I, Meneghin R, Affronti G, Pappalardo F et al. Second cross-clamping after mitral valve repair for degenerative disease in contemporary practice. Eur J Cardiothorac Surg. 2018;54:91-7.

6. El-Eshmawi A, Anyanwu A, Boateng P, Pawale A, Pandis D, Bhatt H, et al. Second cross clamp to perfect degenerative mitral valve repair: decision-making algorithm, safety, and outcomes. J Thorac Cardiovasc Surg. October 16, 2019 [Epub ahead of print].

7. Brown ML, Abel MD, Click RL, Morford RG, Dearani JA, Sundt TM, et al. Systolic anterior motion after mitral valve repair: is surgical intervention necessary? J Thorac Cardiovasc Surg. 2007;133:136-43

8. Imielski B, Malaisrie SC, Pham DT, Kruse J, Andrei AC, Liu M, et al. The impact of intraoperative residual mild regurgitation after repair of degenerative mitral regurgitation. J Thorac Cardiovasc Surg. October 17, 2019 [Epub ahead of print].

9. Dagum P, Timek T, Green GR, Daughters GT, Liang D, Ingels NB Jr, et al Three-dimensional geometric comparison of partial and complete flexible mitral annuloplasty rings. J Thorac Cardiovasc Surg. 2001;122:665-73. 